1. Абушкин Д. Б. Подготовка будущих учителей инфрорматики по дисциплине «Практикум по решению задач на ЭВМ» на основе методики выравнивающего и развивающего обучения : дис. ... канд. пед. наук. М., 2011. 180 с.

2. Забродина О. М. Методика выравнивающе-развивающего обучения информационным технологиям студентов вуза в курсе информатики : дис. ... канд. пед. наук. Волгоград, 2009. $201 \mathrm{c}$.

3. Фалина И. Н. Методика выравнивающего и развивающего обучения информатике в физико-математических классах : автореф. дис. ... канд. пед. наук. М., 2000. 16 с.

УДК 378.011.3-051:811.581

Науч. спец. 13.00 .08

DOI: 10.36809/2309-9380-2020-26-97-100

\section{СОЦИОКУЛЬТУРНАЯ КОМПЕТЕНЦИЯ КАК СРЕДСТВО РЕАЛИЗАЦИИ ПРИНЦИПА КУЛЬТУРОСООБРАЗНОСТИ В ПРОЦЕССЕ ОБУЧЕНИЯ КИТАЙСКОМУ ЯЗЫКУ}

Статья посвящена изучению взаимосвязи социокультурной компетенции и принципа культуросообразности в обучении иностранным языкам на современном этапе. На примерах анализа особенностей трактовки и применения идентичных языковых единиц носителями русской и китайской лингвокультур, а также культурных особенностей ряда грамматических конструкций китайского языка продемонстрирована важность формирования иноязычной социокультурной компетенции в процессе обучения китайскому языку.

Ключевые слова: вторичная языковая личность, социокультурная компетенция, культуросообразность, китайский язык.
4. Беспалько В. П. Педагогика и прогрессивные технологии обучения. М. : Изд-во Ин-та проф. обр. Мин-ва обр. России, 1995. 336 с.

5. Кларин М. В. Технология обучения. Идеал и реальность. Рига : Эксперимент, 1999. 180 с.

6. Богданова А. В. Формирование инфооммационно-коммуникативной компетентности студентов вуза с использованием технологии учебных полей (на примере подготовки бакалавров педагогики) : дис. ... канд. пед. наук. Тольятти, 2011. $246 \mathrm{C}$.

(c) Богданова А. Н., Аршба Т. В., 2020

\title{
SOCIOCULTURAL COMPETENCE AS A MEANS OF IMPLEMENTING THE CULTURAL CONGRUENCE PRINCIPLE IN TEACHING CHINESE
}

The article is devoted to the study of the interrelation between sociocultural competence and the principle of cultural diversity in teaching foreign languages at the present stage. Using the examples of analysis of identical language units interpretation and application by Russian and Chinese native speakers, as well as the cultural characteristics of a number of grammar structures of the Chinese language. The importance of the formation of foreign-language sociocultural competence in teaching Chinese is demonstrated.

Keywords: secondary language personality, sociocultural competence, cultural congruence, the Chinese language.

Изучение китайского языка на сегодняшний день становится всё более популярным в силу укрепления контактов Китая со странами-соседями, в том числе с Россией. Следует отметить, что обучение китайскому языку на территории Российской Федерации происходит не только в рамках специальных программ подготовки высшего образования, оно интегрировано и в процесс обучения в средней школе. Так, с 2019 г. китайский язык официально включен в перечень иностранных языков, которые можно выбрать при сдаче единого государственного экзамена. В силу популяризации данного языка вопросы методики обучения китайскому становятся всё более интересными для специалистов, работающих в сфере образования.

Преподавание иностранных языков на современном этапе ставит целью формирование вторичной языковой личности обучаемого, наличие которой говорит о способности обучаемых быть полноценными участниками межкультурного диалога [1, с. 65]. Вслед за И. И. Халеевой мы трактуем вторичную языковую личность как способность, которая «складывается из овладения вербально-семантическим кодом изучаемого языка, то есть языковой картиной мира носителей этого языка (формирование вторичного языкового сознания) и глобальной (концептуальной) картиной мира» $[1$, c. 68]. Это значит, что любой человек, изучающий иностранный язык, должен не только овладеть комплексом знаний о грамматике, фонетике, лексикологии, стилистике, но и научиться культуросообразно применять эти знания.

Сам по себе педагогический принцип культуросообразности, введенный Адольфом Дистервегом, предполагает необходимость приобщения человека к различным пластам культуры собственного этноса, окружающего человека общества, а также к общемировой культуре [2, с. 303]. Он призван стать подспорьем в адаптации к изменениям, которые постоянно происходят как в нем самом, так и в окружающем его мире, гармонизировать взаимодействие человека со средой, в которую он погружен.

В современном мире, для которого характерным является процесс глобализации, спектр возможностей применения принципа культуросообразности подвергается пересмотpy: данный принцип начинает приобретать межкультурную наполненность, отходя от локально заданных культурных 
реалий в качестве базы. Так, в нынешних реалиях человек с детства активно соприкасается с продуктами различных культур, в силу чего родная культура познается и оценивается им через иные, путем сравнения. Влияние нескольких культур на обучающегося происходит как в образовательном пространстве, так и вне его (в рамках неформального или информального образования). По мнению Е. Г. Таревой, в процессе контакта с культурными явлениями обучающийся их «овеществляет» посредством присваивания продуктов данных культур как личностно значимых, интегрируя их тем самым в собственное пространство ценностных координат [2]. Таким образом, особым содержанием образовательного процесса на сегодняшний день является реализация диалога культур на практике, так что он становится доминантой в процессе формирования личности современного человека.

Реализации идеи обучения языку и культуре в отечественной лингводидактике способствуют культуросообразные подходы, в числе которых, с нашей точки зрения, особый интерес представляет социокультурный подход, призванный акцентировать внимание на социокультурном фоне иноязычного общения. По целевым установкам он ориентирован на «обучение межкультурному иноязычному общению в контексте социально-педагогических доминант педагогики гражданского мира и согласия» [3, с. 62]. Данный подход заключается в стремлении построить многоуровневую модель культуроведческого образования и самообразования, задействуя различные средства изучаемых языков, а также технологии социокультурного образования.

Дидактическая модель данного подхода при этом строится на основе сопоставительного изучения культур и цивилизаций, являющихся родными для изучаемых языков, в контексте их непосредственного и опосредованного историко-культурного взаимовлияния [4]. Таким образом, доминанта обучающей стратегии социокультурного подхода - овладение изучаемыми языками в процессе сопоставительного со-изучения культур данных языков.

Именно социокультурный подход делает особенно актуальным формирование социокультурной компетенции у изучающих иностранные языки. Под социокультурной компетенцией мы понимаем комплекс знаний о национальных ценностях, исторических вехах, религии, поведенческих моделях, обычаях, традициях, языке, достижениях культуры, свойственных определенному обществу и характеризующих его, а также обусловливающих нормы поведения в нем [5, с. 356].

В преподавании иностранных языков вообще, а особенно в преподавании китайского языка в русскоязычной среде, часто затрагивают вопрос о выделении разновидностей культуры, главной из которых считают коммуникативную культуру. «Культура коммуникации - это отраженные в языке национальный менталитет, система ценностей, образ жизни, образ мышления, нормы морали, представления о добре и зле, обычаи и привычки, эстетический вкус и т. д. Все эти культурные фракторы, прежде всего, воплощаются в текущем состоянии языка, его словарном составе, грамматике и прагматике» (здесь и далее перевод с китайского наш. - А. Д., И. А.) [6, с. 148]. В каждом языке существует обусловленный культурой и интуитивно понятный для носителей языка пласт коммуникативных правил, кото- рые необходимо тщательно осваивать людям, изучающим язык как иностранный. Пренебрежение правилами общения может негативно сказаться на возможности успешного построения общения с представителями других культур, стать серьезным препятствием в коммуникации.

Говоря о формировании социокультурной компетенции в процессе обучения китайскому языку, мы делаем особый акцент на то, насколько культуры восточных народов отличаются от европейских, западных, культур в ценностных установках, а также оптимальных стратегиях взаимодействия. Культуры народов Китая и России развивались в течение длительного периода истории, а потому их естественный характер, народные обычаи, бытовые привычки, верования разительно отличаются друг от друга. Эти различия необходимо акцентировать в процессе преподавания, чтобы избежать ошибок, связанных с неосведомленностью в особенностях коммуникативной культуры. Следует приучать обучаемых к сравнительному анализу культурных особенностей Китая и их страны, отраженных в языке, формируя, таким образом, способность ориентироваться в культурной специфике двух стран и строить диалог с максимальным учетом этой специфики.

Одни и те же явления могут быть по-разному отражены и истолкованы в языковых реальностях разных культур. Одним из наиболее ярких примеров языковых несоответствий китайского и русского языков можно назвать систему обращения к членам семьи. Кроме таких терминов родства в русском языке, как «отец», «мать», «сын» и «дочь», трудно подобрать четкие соответствия для прочих обращений к родственникам, существующих в китайском языке, не прибегая к обобщению. Так, в русском языке есть всего лишь одно слово «дядя» для обозначения дяди, каким бы ни было его родственное отношение к говорящему, в то время как в китайском языке существуют специальные термины для обозначения дяди, являющегося старшим братом отца (伯父/bófù/), его младшим братом (叔父/shūfù/), дяди по материнской линии (舅父/jiùfù/), дяди, который является мужем тетки по отцу (姑父/gūfu/) или по матери (姨父/yífù/). Такова же ситуация и со словом «тетя» [6, с. 148]. Поэтому задачей преподавателя китайского языка на этапе освоения лексического материала является акцентирование внимания обучаемых на специфических терминах и реалиях, не имеющих аналогов в родной для обучаемых культуре, а также на различиях в толковании и использовании лексического материала.

Языковые несоответствия китайского и русского языков не исчерпываются лексическим уровнем - на синтаксическом уровне также есть коренные отличия. Основным различием данного плана является порядок слов в предложении: если в русском языке местоположение тех или иных членов предложения может изменяться, то в китайском языке оно фриксировано и отнюдь не всегда совпадает с русским. Это явление обусловлено, по-видимому, и культурологически, так как местоположение сказуемого в китайском языке значительно влияет на смысл высказывания в целом. Ввиду этого в процессе преподавания китайского языка русскоговорящим обучаемым необходимо на примерах пояснять, что в китайском языке фиксированный порядок слов и глаголы в простых предложениях обычно находятся в позиции после подлежащего. Если же подлежащее стоит после глагола, то это указывает на 
появление некоего совершенно нового предмета (например 来客人了 /láikèrénle/ - гость пришел), потому не говорят 来春天了/láichūntiānle/, ведь 春天 /chūntiān/, весна, по сути, не является новым предметом [6, с. 149]. На этом примере видно, насколько важно донести до обучаемых специфику грамматики и синтаксиса китайского языка. Понимание логики построения высказывания обучаемыми позволит уменьшить тенденцию к калькированию грамматических и синтаксических конструкций в процессе перевода с русского на китайский, что облегчит их коммуникативное взаимодействие с представителями китайской лингвокультуры.

Различия языковых систем также могут быть обусловлены обычаями и традициями, отраженными в языке культурными особенностями мышления и менталитета народа. Так, в процессе анализа специфических черт определенной культуры значимую для понимания менталитета данного народа информацию мы можем почерпнуть, изучая животных, которые были тотемами. К примеру, в русской культуре почитается медведь, он является национальным тотемом. Считается, что медведь - чудесное животное, его наделяют такими чертами как сила, здоровье, сердечность, искренность и внимательность. В русской традиции его называют хозяином леса, прародителем всего животного мира. Есть такая русская пословица: «Хозяин в дому, что медведь в бору».

Согласно легендам, медведь обладает волшебными способностями, он может воскреснуть после смерти, понимает человеческую речь, хорошо знает каждого своего родича, может навлечь на человека несчастье или же принести удачу. Медведя также называют «женихом», считается, что увидевшая во сне медведя девушка скоро выйдет замуж. Из русского фрольклора видно, что медведь - символ национальной духовности, трудолюбия, честности, уверенности в себе и своих силах, бесстрашия и т. д.

В свою очередь для китайской культуры почитаемым, тотемным животным является дракон (龙 /lóng/). Его считают знаком величия власти. Древних императоров в знак их величественности называли драконоликими (龙颜 /lóngyán/), их чертоги - дворцом царя драконов (龙宫 /lónggōng/), парадный наряд императора - драконьим облачением (龙袍 /lóngpáo/). Китайцы называют себя потомками дракона (龙的传人 /lóngdechuánrén/). Безусловно, соотнесение образа дракона с фигурой императора является следствием многолетнего феодального устройства общества, царившего в Китае, что, однако, дает возможность проследить истоки преклонения перед данным животным.

Помимо символа императорской власти, дракон является символом красоты созданных человеком вещей. Так, орнамент из драконов украшает колонны главного входа в императорский дворец, Врат Небесного Спокойствия; известны и «девять драконов» Запретного города. Драконов можно увидеть и в произведениях народного искусства. Другими отражениями значимости тотема в народной культуре Китая являются: танец извивающегося дракона, которым в древности вызывали дождь; жонглирование фонарями в форме дракона на ежегодном Празднике Весны; соревнования драконовых лодок на Праздник начала лета.

В китайском языке обороты, в которых содержится иероглиф 龙 /lóng/, служат для выражения похвалы и ценности. Так, например, выражение 龙肝凤髓 /lónggān fèngsuľ/ (печень дракона и костный мозе феникса) обозначает изысканные деликатесы; 龙争虎斗 /lóngzhēng hǔdòu/ (борьба дракона и тигра) используется для характеристики яростной схватки; 龙蟠虎踞 /lóngpánhǔjù/ (где свернулся дракон и притаился тигр) говорит о неприступной и опасной местности; 龙腾虎跃 /lóng téng hǔ yuè/ (как дракон взлетает, как тигр прыгает) указывает на совершение славного деяния. В именах китайцев также часто фигурирует иероглифф 龙 /lóng/ (например, 李小龙/lǐ xiǎolóng/, 成龙 /chénglóng/ и др.), выражая родительские надежды и ожидания относительно славного будущего потомков. Дракон является символом постоянного самоусовершенствования китайской нации, символом процветания и могущества, передающимся из поколения в поколение.

Анализируя значения описанных выше тотемов в культуре двух сравниваемых стран, легко заметить различия менталитета русского и китайского. Для китайцев слово «медведь» (熊 /xióng/) хоть и фигурирует в некоторых выражениях, обладающих положительной коннотацией (например, 虎背熊腰 /hǔbèixióngyāo/ - богатырское сложение), но чаще несет негативный оттенок (например, 熊包 /xióngbāo/ - mynuua, 熊样 /xióngyàng/ - cвupenь/ŭ, 熊德行 (xióngdéxíng/—-трусость). Китайцы считают медведя глупым и неуклюжим, а потому еще и невероятно простодушным, он действует необдуманно. Из этого видно, что китайцы обращают внимание только на внешний облик медведя, в то время как русские считают важным его внутренний мир.

Для русских же слово «дракон» обладает четко выраженной негативной коннотацией. Оно накрепко связано с образом несущих разрушение чудовищ, которых в народных сказках повергают богатыри и силачи. Изображение поверженного дракона в русской культуре - это символ победы над злом. Говоря о фразеологизмах со словом «дракон» в русском языке, следует отметить, что они немногочисленны и в абсолютном большинстве обладают негативной коннотацией. Можно привести следующие примеры: драконовы законы (излишне жестокие законы), посеять зубы дракона (посеять вражду).

Очевидно, что толкование охарактеризованных нами выше тотемов кардинально отличается в русской и китайской культурах. Поэтому в процессе изучения культурно специфической лексики на занятиях обязательно следует пояснить связанные с ней культурные коннотации, разбираться в разнице трактовок носителями русской и китайсклой лингвокультур, иначе на результат обучения может негативно повлиять интерференция родной для обучаемых культуры.

Как заметил Чэнь Гуанлэй, «Что до процесса овладения языком и его преподавания, то в нем невозможно разделить понимание языка и отраженной в нем культуры» [7, с. 146]. Это подчеркивает значимость интеграции культурного компонента в процесс преподавания иностранных языков. Так, при наличии сформированной социокультурной компетенции обучаемому проще строить процесс освоения и запоминания новой лексики.

Рассмотрим, как именно наличие социокультурной компетенции может способствовать освоению китайского языка на примере слова 元宵/yuánxiāo/. Зная, что в 15-й день 1-го лунного месяца китайцы с древности отмечали традиционный 
праздник, который назывался 元宵节/yuánxiāojié/ (Праздник фонарей), обучаемый осознает, что в честь этого праздника и получили свое название 元宵/yuánxiāo/ - и шарики из риса с разнообразной начинкой, которые являются традиционным блюдом в этот день. Очевидно, что такой подход позволяет более полно охватить языковую картину мира и лучше понять культуру изучаемого языка. Вследствие этого у обучаемых расширяется потенциал ведения межкультурного диалога [6, с. 149]. Более того, такой подход позволяет повысить качество восприятия информации на китайском языке и грамотно адаптировать ее для восприятия при переводе.

Для успешного формирования социокультурной компетенции обучаемых важно учитывать их уровень знаний, возраст, жизненный опыт и т. д. Для обучаемых с высоким уровнем знаний можно расширять и углублять культурный компонент преподавания языка, вплоть до введения специальных занятий по культуре Китая. Для тех же, чей уровень довольно низок, следует максимально облегчить момент интеграции культурного компонента и не акцентировать на нем внимание слишком сильно [6, с. 149]. Такой подход позволяет в значительной мере оптимизировать процесс обучения и сделать его более плодотворным, что в свою очередь демонстрирует важность дифференцированного подхода к подаче материала в зависимости от уровня личной культуры обучаемых.

\section{УДК 378}

Науч. спец. 13.00 .08

DOI: $10.36809 / 2309-9380-2020-26-100-103$

\section{ФОРМИРОВАНИЕ КРИТИЧЕСКОЙ ОСОЗНАННОСТИ В МЕЖКУЛЬТУРНОЙ КОММУНИКАЦИИ ПРИ ПОДГОТОВКЕ УЧИТЕЛЯ ИНОСТРАННОГО ЯЗЫКА}

В статье критическая межкультурная осознанность рассматривается как компонент межкультурной коммуникативной компетенции учителя иностранного языка. Показано, что критическая осознанность в межкультурной коммуникации базируется на сложной совокупности нескольких видов знания (языкового, метаязыкового, социокультурного; декларативного, процедурного) и ценностно-смыслового отношения к культурам родного и иностранного языков. Обсуждаются пути формирования межкультурной осознанности в процессе профессиональной подготовки педагогов. Обосновывается необходимость усиления сравнительно-сопоставительного аспекта в преподавании языка и культуры в вузе, развития у будущих учителей умений сопоставительного лингвистического и лингводидактического анализа, повышения уровня дискурсивной компетенции в области межкультурного взаимодействия.

Ключевые слова: иноязычное образование, профессиональная подготовка педагога, межкультурная компетентность, сопоставительный культурологический анализ, критический дискурс-анализ.
1. Гальскова Н. Д., Гез Н. И. Теория обучения иностранным языкам: Лингводидактика и методика : учеб. пособие для студ. лингв. ун-тов и фак. ин. яз. высш. пед. учеб. заведений. М. : Изд. центр «Академия», 2004. 336 с.

2. Тарева Е. Г. Система культуросообразных подходов к обучению иностранному языку // Язык и культура. 2017. № 40. C. 302-320.

3. Сафонова В. В. Изучение языков международного общения в контексте диалога культур и цивилизаций. Воронеж : Истоки, 1996. 237 с.

4. Сафонова В.В.Культуроведческий ракурс современного языкового образования // Учен. зап. Нац. о-ва прикладной лингвистики. 2013. № 2 (2). С. 26-46.

5. Чиркова В. М. Теоретическая модель формирования социокультурной компетенции // Вестн. Костром. гос. ун-та. 2008. № 14 (4) С. 356-360.

6. 王勇. 中俄文化差异与对俄汉语教学 // 学理论. 2009. № 8. 第148-149 页。

7. 陈光磊. 语言教学与文化背景知识的相关性. 语 言教学与研. 1987. 第2期. 第146页。

(С) Дворцова А. Н., Акиншева И. П., 2020

\section{TRAINING OF CRITICAL INTERCULTURAL AWARENESS IN FOREIGN LANGUAGE TEACHERS' EDUCATION}

The paper regards critical intercultural awareness as the component of second language teachers' intercultural communicative competence. It is stated that intercultural awareness is based upon the complex unity of several types of knowledge (linguistic, metalinguistic, socio-cultural; declarative, procedural) and meaning-value-attitude assumptions regarding the first language and the second language cultures. The paper discusses the ways of intercultural awareness training as part of second language teachers' education. The key role of the comparative studies approach in teachers' training is highlighted. It is shown that enhanced skills of comparative linguistic analysis and comparative cultural analysis as well as enhanced intercultural discourse competence in second language teachers provide the necessary background for critical intercultural awareness.

Keywords: foreign language education, teachers' professional training, intercultural competence, comparative cultural analysis, critical discourse analysis. 